\title{
Clinical and echocardiographic outcomes after surgery for severe isolated tricuspid regurgitation
}

\author{
Joon Bum Kim, MD, Sung-Ho Jung, MD, Suk Jung Choo, MD, PhD, Cheol Hyun Chung, MD, PhD, and \\ Jae Won Lee, MD, PhD
}

\begin{abstract}
Objective: Few studies have investigated the outcomes after surgical correction of severe isolated tricuspid regurgitation.
\end{abstract}

\begin{abstract}
Methods: The medical records of 51 consecutive patients (aged $55.8 \pm 12.9$ years, 25 male) who underwent tricuspid valve surgery at the Asan Medical Center between September 1996 and July 2010 were evaluated retrospectively. All patients had severe isolated tricuspid regurgitation but no significant left-sided cardiac disease or history of heart surgery.
\end{abstract}

\begin{abstract}
Results: Tricuspid valve repair $(\mathrm{n}=37,72.5 \%)$ or replacement $(\mathrm{n}=14,27.5 \%)$ was performed. Replacement involved mechanical $(n=4)$ or bioprosthetic valves $(n=10)$. One early death occurred $(2.0 \%)$. During a median follow-up period of 47.4 months (interquartile range, 10.4-61.4 months), 9 late deaths, 3 readmissions for congestive heart failure, 2 heart transplantations, and 1 tricuspid valve reoperation occurred. Overall and event-free survivals at 5 years were $83.5 \% \pm 5.4 \%$ and $77.3 \% \pm 6.1 \%$, respectively. In the multivariable Cox regression analysis, preoperative hemoglobin $(P=.045)$, serum bilirubin $(P=.008)$, estimated glomerular filtration rate $(P=.045)$, and systolic right ventricular dimension $(P=.047)$ were significant and independent determinants of clinical outcome. On serial echocardiographic evaluations (median follow-up period, 28.5 months; interquartile range, 18.9-68.7 months), moderate-to-severe tricuspid regurgitation was detected in 21 patients $(41 \%)$. Severe tricuspid regurgitation after tricuspid valve repair or bioprosthetic valve replacement was a significant predictor of poor event-free survival, even after adjustment for preoperative risk factors $(P=.036)$.
\end{abstract}

Conclusions: In the present cohort, preoperative anemia, renal/hepatic dysfunction, right ventricular dilatation, and significant postoperative tricuspid regurgitation were associated with poor outcomes. Timely surgery is advisable in patients with severe isolated tricuspid regurgitation before the development of anemia, organ dysfunction, or right ventricular dilatation. (J Thorac Cardiovasc Surg 2013;146:278-84)

Although severe tricuspid regurgitation (TR) is associated with a poor prognosis, ${ }^{1}$ current guidelines do not sufficiently specify the optimal timing for surgery in patients with severe isolated $\mathrm{TR}^{2,3}$ This is partly attributable to a lack of appropriate data because there is a relative paucity of patients with isolated TR compared with patients with left-sided valvular heart disease. To date, few studies have investigated the clinical outcomes after isolated tricuspid valve (TV) surgery. ${ }^{4-6}$

Isolated TV surgery has been associated with a high rate of mortality, and the long-term outcomes are poor. Clinicians therefore tend to delay surgery until medical treatment fails to alleviate the symptoms of advanced heart failure. ${ }^{7-10}$

From the Department of Thoracic and Cardiovascular Surgery, Asan Medical Center, University of Ulsan College of Medicine, Seoul, South Korea.

Disclosures: Authors have nothing to disclose with regard to commercial support.

Received for publication Feb 13, 2012; revisions received March 18, 2012; accepted for publication April 6, 2012; available ahead of print Aug 6, 2012.

Address for reprints: Jae Won Lee, MD, PhD, Department of Thoracic and Cardiovascular Surgery, Asan Medical Center, University of Ulsan College of Medicine, 388-1 Pungnap-dong Songpa-gu, Seoul 138-736, South Korea (E-mail: jwlee@ amc.seoul.kr).

0022-5223/\$36.00

Crown Copyright $\odot 2013$ Published by Elsevier Inc. on behalf of The American Association for Thoracic Surgery

http://dx.doi.org/10.1016/j.jtcvs.2012.04.019
Consequently, patients who are referred for surgery are typically medically compromised and at high risk, which may explain the poor surgical outcomes. ${ }^{11}$ Further research to evaluate the surgical outcomes and prognostic factors in this unique population is therefore warranted to establish the optimal timing for surgery and thereby improve surgical outcomes. The present study evaluates the long-term outcomes in patients undergoing first-time TV surgery for severe isolated TR and identifies prognostic indicators.

\section{MATERIALS AND METHODS Patients}

Between September 1996 and July 2010, a total of 486 patients underwent TV surgery for severe TR at the Asan Medical Center in Seoul, Korea. Patients who underwent concomitant left-sided valve surgery $(\mathrm{n}=359)$, coronary artery bypass $(n=15)$, or correction of a congenital heart defect $(n=20)$ were excluded from the present analyses. Patients with the Ebstein anomaly $(\mathrm{n}=1)$, active endocarditis $(\mathrm{n}=5)$, or a history of cardiac surgery $(\mathrm{n}=35)$ were also excluded. This resulted in a sample of 51 consecutive patients who had undergone first-time isolated TV surgery for severe TR. Surgery was determined at the attending physician's discretion by taking into consideration age, symptoms, and other comorbidities of the patients. The study was approved by the institutional ethics committee/review board of the Asan Medical Center, and the requirement for informed patient consent was waived in view of the retrospective nature of the study. 


\section{Abbreviations and Acronyms \\ $\mathrm{CHF}=$ congestive heart failure \\ $\mathrm{RV}=$ right ventricle \\ $\mathrm{TR}=$ tricuspid regurgitation \\ $\mathrm{TV}=$ tricuspid valve}

\section{Echocardiography}

Two-dimensional echocardiography and Doppler color-flow imaging were performed using a Hewlett-Packard Sonos 2500 or a 5500 imaging system equipped with a $2.5 \mathrm{MHz}$ transducer (Hewlett-Packard, Andover, Mass). Echocardiography was performed in all patients within the 2-month preoperative period. The degree of TR was evaluated using the apical 4-chamber view. Mild, moderate, and severe TR were defined by a distal jet area of less than $5 \mathrm{~cm}^{2}, 5$ to $10 \mathrm{~cm}^{2}$, and more than $10 \mathrm{~cm}^{2}$, respectively. ${ }^{12}$ Right ventricle (RV) end-diastolic and end-systolic dimensions were measured in the RV outflow tract from the parasternal view.

\section{Surgical Procedures}

Surgery involved a median sternotomy $(n=41)$ or a port-access right minithoracotomy $(n=10)$, depending on the preference of the surgeon. The sternotomy approach involved conventional ascending aorta and bicaval cannulation. The minimally invasive approach involved peripheral cannulation through the right internal jugular vein, right femoral vein, and right femoral artery. TV surgery was performed under beating heart $(\mathrm{n}=11)$ or cardioplegic arrest $(\mathrm{n}=40)$ conditions. TV repair $(\mathrm{n}=37)$ or replacement $(n=14)$ was performed. In cases of TV replacement, leaflets and subvalvular structures were preserved. The decision on whether to perform TV repair or replacement was influenced by the preoperative clinical status and echocardiographic parameters of each individual patient. However, the final decision was made at the discretion of the attending surgeon.

\section{Follow-up}

Follow-up data were obtained until the end of August 2011 through 3- to 6-month interval visits to the outpatient clinic. For those who were followed up at other hospitals $(\mathrm{n}=9)$, clinical information was obtained from telephone contacts. Data on vital status, dates of death, and causes of death were confirmed by accessing the Korean National Registry of Vital Statistics. All deaths were considered to have been of cardiac origin unless a noncardiac origin had been established clinically or determined at autopsy. Early mortality was defined as the occurrence of death within 30 days of surgery.

The primary outcomes of interest were all-cause death, requirement for $\mathrm{TV}$ reoperation or heart transplantation, and readmission due to congestive heart failure (CHF). For the purposes of the present study, CHF was defined as the presence of resting dyspnea and a requirement for intravenous diuretic therapy.

\section{Statistics}

Categoric variables are presented as frequencies and percentages, and were compared using Fisher exact tests. Continuous variables are expressed as the mean \pm standard deviation or the median and the range, and were compared using the Mann-Whitney $U$ test. Kaplan-Meier curves were used to delineate the survival or freedom from major adverse events. Log-rank tests were used to compare between-group differences in these rates. For the multivariate analyses, Cox proportional hazard models were used to determine the risk factors for mortality and adverse events. Baseline variables listed in Tables 1 and 2 were evaluated in a univariate model. Variables with a $P$ value of .20 or less in univariate analyses were considered candidates for the multivariable Cox models. The multivariate analyses involved a backward elimination technique, and only variables with a $P$ value less than .10 were used in the final model. The Statistical Package for the Social Sciences version 14.0 (SPSS Inc, Chicago, Ill) was used for the statistical analyses.

\section{RESULTS}

\section{Baseline Characteristics}

The mean age at surgery was $55.8 \pm 12.9$ years, and 25 patients $(49.0 \%)$ were male. Sixteen patients $(31.4 \%)$ had functional class III or IV heart failure according to the New York Heart Association classification, and 3 patients (5.9\%) had liver cirrhosis. Eight patients $(15.7 \%)$ had a history of blunt chest trauma. Twenty-seven patients $(52.9 \%)$ had isolated annular dilatation with $(\mathrm{n}=20)$ or without $(\mathrm{n}=7)$ leaflet tethering, and 21 patients $(41.2 \%)$ had leaflet prolapse. Leaflet thickening was observed in 4 patients. Baseline demographic, laboratory, and echocardiographic profiles are summarized in Tables 1 and 2. Patients who underwent TV replacement were more likely to have advanced heart failure symptoms, more severe TR, and larger systolic and diastolic RV dimensions, and were less likely to undergo a concomitant Maze procedure in the presence of atrial fibrillation than patients who underwent TV repair.

Of the 37 patients who underwent TV repair, 34 underwent ring annuloplasty and 1 underwent DeVega annuloplasty. In 22 of these patients, TV repair was combined with a total of $24 \mathrm{TV}$ leaflet procedures. These procedures were new chordae formation $(\mathrm{n}=9)$, commissuroplasty $(\mathrm{n}=6)$, leaflet extension $(\mathrm{n}=4)$, the Alfieri technique $(\mathrm{n}=4)$, and papillary muscle reattachment $(\mathrm{n}=1)$. For ring annuloplasty, rigid $(n=12)$ or flexible $(n=18)$ rings, or annuloplasty bands $(n=4)$ were used. For the 14 patients who underwent TV replacement, mechanical $(n=4)$ or bioprosthetic $(\mathrm{n}=10$; pericardial valves in 8 and porcine valves in 2) valves were implanted.

\section{Early Surgical Outcomes}

The mean aortic clamping and cardiopulmonary bypass times were $57.7 \pm 26.2$ minutes and $100.8 \pm 41.0$ minutes, respectively. No significant differences in these durations were observed between the TV repair and replacement groups $(P=.48$ and .23 , respectively).

One early death $(2.0 \%)$ occurred on the second postoperative day in a patient who had undergone bioprosthetic TV replacement. This was caused by severe RV dysfunction. Table 3 summarizes the early postoperative outcomes. No significant differences in early postoperative complications were observed between the TV repair and replacement groups.

\section{Late Outcomes}

Follow-up was complete $(100 \%)$ with a median follow-up period of 47.4 months (interquartile range, 10.4-61.4 months). During this period, 8 late deaths 
TABLE 1. Baseline demographic and laboratory characteristics of the study cohort

\begin{tabular}{|c|c|c|c|}
\hline & Repair & Replacement & $\begin{array}{c}P \\
\text { value }\end{array}$ \\
\hline No. of patients & 37 & 14 & \\
\hline Age, y & $55.7 \pm 13.8$ & $56.1 \pm 10.7$ & .92 \\
\hline Male gender, $\mathrm{n}(\%)$ & $19(51.4)$ & $6(42.9)$ & .76 \\
\hline Diabetes mellitus, n (\%) & $6(16.2)$ & $2(14.3)$ & $>.99$ \\
\hline Hypertension, n (\%) & $10(27.0)$ & $3(21.4)$ & $>.99$ \\
\hline Atrial fibrillation, $\mathrm{n}(\%)$ & $20(54.0)$ & $6(42.9)$ & .54 \\
\hline Maze procedure, n (\%) & $9(24.3)$ & 0 & $.049 *$ \\
\hline History of stroke, $\mathrm{n}(\%)$ & $1(2.7)$ & 0 & $>.99$ \\
\hline Liver cirrhosis, $\mathrm{n}(\%)$ & $3(8.1)$ & 0 & .27 \\
\hline Chronic lung disease, n (\%) & $1(2.7)$ & $1(7.1)$ & .47 \\
\hline NYHA functional class, $\mathrm{n}(\%)$ & & & $.029^{*}$ \\
\hline I & $9(24.3)$ & 0 & \\
\hline II & $20(54.0)$ & $6(42.9)$ & \\
\hline III & $5(13.5)$ & $3(21.4)$ & \\
\hline IV & $3(8.1)$ & $5(35.7)$ & \\
\hline $\begin{array}{l}\text { History of blunt chest trauma, } \\
\mathrm{n}(\%)\end{array}$ & $4(10.8)$ & $4(28.6)$ & .12 \\
\hline Hemoglobin, g/dL & $13.0 \pm 2.3$ & $12.3 \pm 2.0$ & .31 \\
\hline Platelet count, $\times 1000 / \mu \mathrm{L}$ & $176.8 \pm 68.2$ & $179.2 \pm 80.2$ & .91 \\
\hline Albumin, $\mathrm{g} / \mathrm{dL}$ & $3.9 \pm 0.5$ & $3.8 \pm 0.5$ & .50 \\
\hline Creatinine, mg/dL & $1.1 \pm 0.6$ & $0.8 \pm 0.2$ & .13 \\
\hline $\mathrm{eGFR}, \mathrm{mL} / \mathrm{min} / 1.73 \mathrm{~m}^{2}$ & $74.7 \pm 35.3$ & $84.2 \pm 12.7$ & .33 \\
\hline Bilirubin, mg/dL & $1.2 \pm 0.5$ & $1.2 \pm 0.7$ & .79 \\
\hline $\begin{array}{l}\text { B-type natriuretic peptide, } \\
\mathrm{pg} / \mathrm{mL}\end{array}$ & $259.2 \pm 293.2$ & $561.7 \pm 391$ & .31 \\
\hline C-reactive protein, $\mathrm{g} / \mathrm{dL}$ & $0.3 \pm 0.6$ & $1.3 \pm 1.5$ & .090 \\
\hline
\end{tabular}

NYHA, New York Heart Association; $e G F R$, estimated glomerular filtration rate. $* P<.05$.

( 4 cardiac, 3 unknown, and 1 malignancy), 4 readmissions due to $\mathrm{CHF}$, and 2 heart transplantations occurred. One patient from the TV repair group underwent TV replacement for severe TR 1 year after initial surgery. The overall survival at 5 years was $83.5 \% \pm 5.4 \%$. Survival free of CHF, heart transplantation, or TV reoperation was $77.3 \% \pm 6.1 \%$ at 5 years. Figure 1 depicts overall survival and event-free survival according to surgery type. No significant differences in survival or event-free survival were observed between the TV repair and replacement groups $(P=.22$ and .59 , respectively).

Multivariate Cox regression analysis showed that the preoperative levels of hemoglobin, estimated glomerular filtration rate, and bilirubin, and RV end-systolic dimension were significant and independent determinants of the composite adverse outcome (death, CHF, heart transplantation, and TV reoperation) (Table 4).

At the end of follow-up, 42 patients were alive. Of them, New York Heart Association functional class could be assessed in 40 patients. In 2 patients, functional class could not be assessed because of multiple injuries (traffic accident) and cancer chemotherapy requiring hospitalization. Figure 2 shows comparisons of preoperative and last
TABLE 2. Baseline echocardiographic data of the study cohort

\begin{tabular}{lccc}
\hline & $\begin{array}{c}\text { Repair } \\
(\mathbf{n = 3 7 )}\end{array}$ & $\begin{array}{c}\text { Replacement } \\
(\mathbf{n = 1 4 )}\end{array}$ & $\begin{array}{c}\boldsymbol{P} \\
\text { value }\end{array}$ \\
\hline Echocardiographic data & & & \\
TR jet area, cm ${ }^{2}$ & $21.6 \pm 5.8$ & $36.6 \pm 18.1$ & $.050^{*}$ \\
TV annular dilatation, n (\%) & $30(81.1)$ & $13(92.9)$ & .30 \\
TV tethering, n (\%) & $17(45.9)$ & $7(50.0)$ & $>.99$ \\
Leaflet abnormality, n (\%) & $17(45.9)$ & $7(50.0)$ & $>.99$ \\
$\quad$ Prolapse & $15(40.5)$ & $5(35.7)$ & .75 \\
$\quad$ Thickening & $1(2.7)$ & $2(14.3)$ & .12 \\
$\quad$ Thickening + prolapse & $1(2.7)$ & 0 & $>.99$ \\
RVIDs, mm & $31.2 \pm 4.1$ & $37.9 \pm 6.0$ & $.002 *$ \\
RVIDd, mm & $38.7 \pm 5.8$ & $43.2 \pm 7.5$ & .053 \\
RV dysfunction, n (\%) & $13(35.1)$ & $7(50.0)$ & .36 \\
RV dilatation, n (\%) & $31(83.8)$ & $13(92.9)$ & .66 \\
IVC plethora, n (\%) & $20(54.1)$ & $12(85.7)$ & .053 \\
Hepatic vein reversal flow, n (\%) & $27(73.0)$ & $12(85.7)$ & .34 \\
LV ejection fraction, \% & $57.8 \pm 7.9$ & $59.6 \pm 6.9$ & .45 \\
LVIDs, mm & $31.1 \pm 6.9$ & $28.6 \pm 5.9$ & .24 \\
LVIDd, mm & $46.6 \pm 6.4$ & $42.8 \pm 7.0$ & .070 \\
TR PG (peak), mm Hg & $27.5 \pm 9.0$ & $22.6 \pm 7.7$ & .095 \\
\hline
\end{tabular}

$T R$, Tricuspid regurgitation; $T V$, tricuspid valve; $R V I D s$, right ventricular end-systolic dimension; $R V I D d$, right ventricular end-diastolic dimension; $R V$, right ventricle; $I V C$, inferior vena cava; $L V$, left ventricle; $L V I D s$, left ventricular end-systolic dimension; $L V I D d$, left ventricular end-diastolic dimension; $P G$, pressure gradient. $* P<.05$.

follow-up New York Heart Association functional class. Patients showed significant improvements in functional classes at the end of follow-up $(P<.001)$ compared with their preoperative status.

\section{Postoperative Tricuspid Valve Function}

Of the 6-month survivors $(\mathrm{n}=47), 37$ patients $(78.7 \%)$ underwent late ( $>6$ months) postoperative echocardiographic evaluation. The median duration of echocardiographic follow-up was 28.5 months (interquartile range, 18.9-68.7 months). The preoperative and final follow-up echocardiographic parameters are summarized in Table 5. At the final follow-up, systolic and diastolic RV

TABLE 3. Early postoperative outcomes in the study cohort

\begin{tabular}{lcccr}
\hline \multicolumn{1}{c}{ Variables, n (\%) } & $\begin{array}{c}\text { Total } \\
(\mathbf{n = 5 1 )}\end{array}$ & $\begin{array}{c}\text { Repair } \\
(\mathbf{n}=\mathbf{3 7})\end{array}$ & $\begin{array}{c}\text { Replacement } \\
(\mathbf{n}=\mathbf{1 4})\end{array}$ & $\begin{array}{c}\boldsymbol{P} \\
\text { value }\end{array}$ \\
\hline Early or in-hospital mortality & $1(2.0)$ & 0 & $1(7.1)$ & .10 \\
$\begin{array}{l}\text { No. of patients with major } \\
\quad \text { complications }\end{array}$ & $10(19.6)$ & $6(16.2)$ & $4(28.6)$ & .32 \\
$\quad$ Bleeding reexploration & $5(9.8)$ & $3(8.1)$ & $2(14.3)$ & .61 \\
Acute renal failure & $3(5.9)$ & $2(5.4)$ & $1(7.1)$ & $>.99$ \\
Low cardiac output & $5(9.8)$ & $4(10.8)$ & $1(7.1)$ & .69 \\
$\quad$ syndrome & & & & \\
$\quad$ Wound infection & $1(2.0)$ & $1(2.7)$ & 0 & $>.99$ \\
$\quad$ Pulmonary infection & $1(2.0)$ & $1(2.7)$ & 0 & $>.99$ \\
Permanent pacer & $2(3.9)$ & $2(5.4)$ & 0 & $>.99$ \\
$\quad$ implantation & & & & \\
$\quad$ Ventricular tachycardia & $1(2.0)$ & $1(2.7)$ & 0 & $>.99$ \\
$\quad$ Sepsis, multiorgan failure & $1(2.0)$ & $1(2.7)$ & 0 & $>.99$ \\
\hline
\end{tabular}



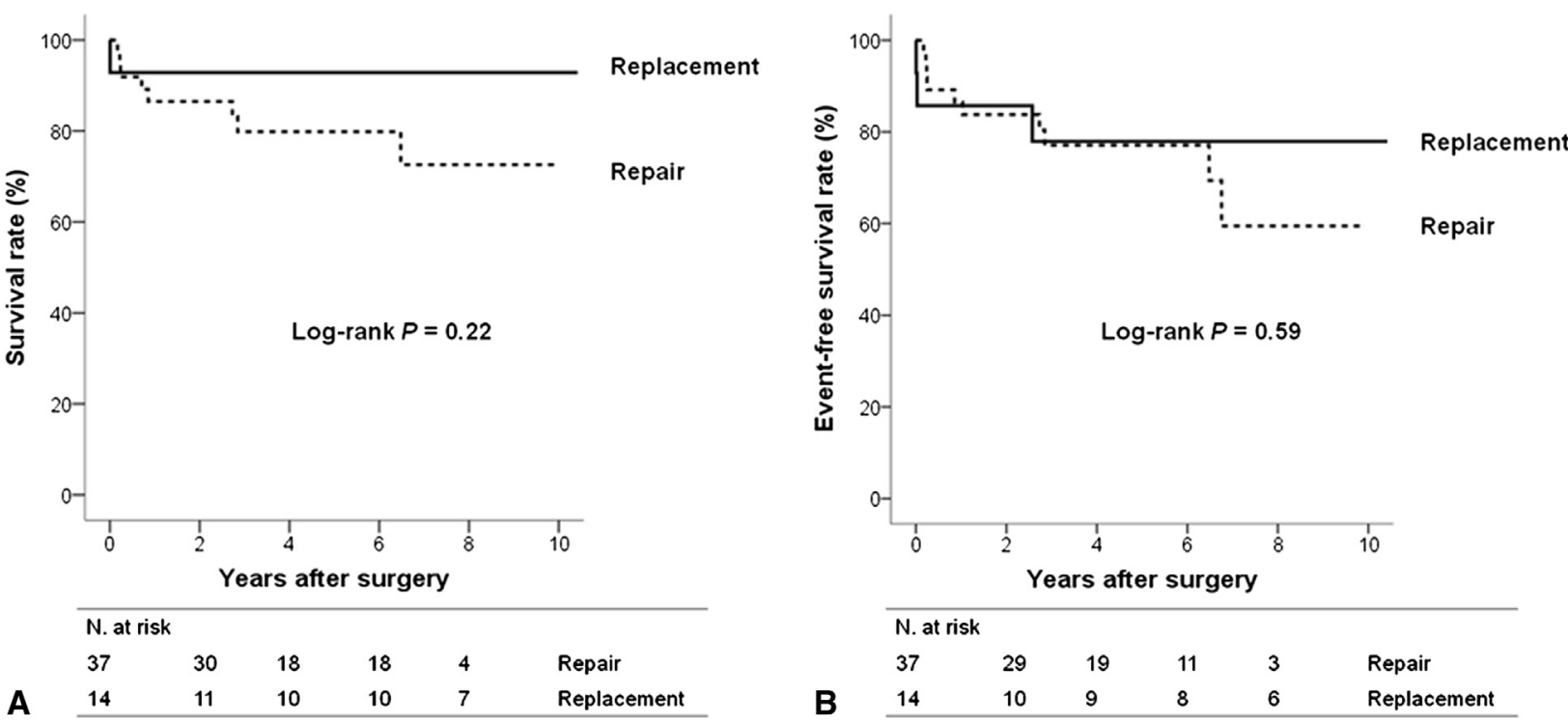

FIGURE 1. Survival (A) and event-free survival (B) curves. The survival at 5 years was $79.8 \% \pm 6.9 \%$ in the repair group and $92.9 \% \pm 6.9 \%$ in the replacement group. Major events were defined as tricuspid reoperation, heart transplantation, and readmission due to CHF.

dimensions, TR jet area, and TR degree were significantly reduced compared with the values obtained at the preoperative assessment. During the serial follow-up echocardiographic evaluations, moderate-to-severe TV dysfunction developed in 21 patients at least once (moderate, $\mathrm{n}=15$; severe, $n=6$ ). Figure 3 shows freedom from TR according to the TR degree and type of TV surgery. No significant difference in TR-free rate was observed between the TV repair and replacement groups. However, in the TV replacement group, TR recurrence occurred only in patients with a bioprosthetic implant $(\mathrm{n}=4)$. Of 4 bioprosthetic valve dysfunctions, 3 were from pericardial valves and 1 was from a porcine valve. In the group of patients who underwent ring annuloplasty $(\mathrm{n}=34)$, there were no significant differences in freedom from moderate-to-severe TR $(P=.64)$ or freedom from severe TR $(P=.51)$ among the use of rigid rings, flexible rings, and annuloplasty bands. Severe postoperative TR was significantly associated with major adverse outcomes, as shown in Figure 4 $(P=.036)$.

TABLE 4. Multivariate Cox-regression analysis for event-free survival

\begin{tabular}{lccc}
\hline & $\begin{array}{c}\text { Hazard } \\
\text { ratio }\end{array}$ & $\begin{array}{c}\mathbf{9 5} \% \text { Confidence } \\
\text { interval }\end{array}$ & $\begin{array}{c}\boldsymbol{P} \\
\text { value }\end{array}$ \\
\hline Hemoglobin (by $1 \mathrm{~g} / \mathrm{dL}$ increment) & 0.77 & $0.60-0.99$ & .045 \\
eGFR (by $10 \mathrm{~mL} / \mathrm{min} / 1.73 \mathrm{~m}^{2}$ & 0.67 & $0.45-0.99$ & .045 \\
$\quad$ increment) & & & \\
Bilirubin (by 0.1 $\mathrm{mg} / \mathrm{dL}$ increment) & 6.26 & $1.63-24.1$ & .008 \\
RVIDs (by 1-mm increment) & 1.17 & $1.01-1.36$ & .047 \\
\hline $\begin{array}{l}\text { eGFR, Estimated glomerular filtration rate; } R V I D s, \text { right ventricular end-systolic } \\
\text { dimension. }\end{array}$
\end{tabular}

\section{DISCUSSION}

In addition to the relative paucity of patients with primary isolated TR compared with patients with left-sided valvular heart disease, there are 2 main reasons why isolated TV surgery is uncommon in clinical practice. First, the risk of mortality with isolated TV surgery is reported to be high, sometimes unacceptably so, and thus clinicians tend to hesitate in referring for surgical intervention. Second, unlike left-sided valvular heart disease, isolated TR can be tolerated relatively well and over a long period of time, even when severe.

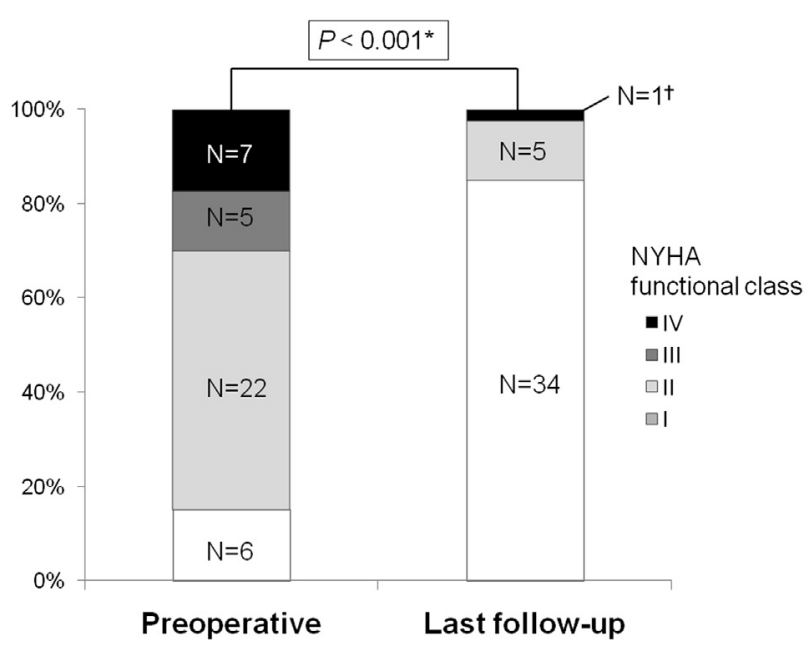

FIGURE 2. New York Heart Association functional class before surgery and at last-follow-up. $* P<.001$ by marginal homogeneity test. $\dagger$ A patient who had tuberculous destroyed lung before surgery. NYHA, New York Heart Association. 
TABLE 5. Comparison of preoperative and final follow-up (>6 months postoperatively) echocardiographic evaluation

\begin{tabular}{lccc}
\hline & $\begin{array}{c}\text { Preoperative } \\
(\mathbf{n}=\mathbf{5 1})\end{array}$ & $\begin{array}{c}\text { Final follow-up }>6 \text { mo } \\
(\mathbf{n}=\mathbf{3 7})\end{array}$ & $\begin{array}{c}\boldsymbol{P} \\
\text { value }\end{array}$ \\
\hline LV ejection fraction, \% & $58.2 \pm 7.6$ & $57.9 \pm 9.4$ & .77 \\
RVIDs, mm & $32.7 \pm 5.3$ & $28.4 \pm 9.8$ & $.034^{*}$ \\
RVIDd, mm & $40.0 \pm 6.5$ & $35.5 \pm 9.3$ & $.044^{*}$ \\
RV dilatation, n (\%) & $44(86.3)$ & $16(43.2)$ & $<.001^{*}$ \\
RV dysfunction, n (\%) & $20(39.2)$ & $9(24.3)$ & .21 \\
TR PG (peak), mm Hg & $26.3 \pm 8.9$ & $28.1 \pm 13.0$ & .21 \\
TR jet area, cm ${ }^{2}$ & $24.5 \pm 11.0$ & $5.9 \pm 5.3$ & $<.001^{*}$ \\
TR grade & & & $<.001^{*}$ \\
$\quad$ None to trace & 0 & $10(27.0)$ & \\
$\quad$ Mild & 0 & $13(35.1)$ & \\
Moderate & 0 & $10(27.0)$ & \\
Severe & $51(100.0)$ & $4(10.8)$ & \\
\hline
\end{tabular}

Wilcoxon-signed rank test was used for continuous variables, and McNemar or marginal homogeneity tests were used for categoric variables. $L V$, Left ventricle; RVIDs, right ventricular end-systolic dimension; RVIDd, right ventricular end-diastolic dimension; $R V$, right ventricle; $T R$, tricuspid regurgitation; $P G$, pressure gradient. $* P<.05$.

Current American College of Cardiology/American Heart Association guidelines suggest that TV replacement or annuloplasty is reasonable for severe primary TR when "symptomatic" (class IIa recommendation and level of evidence C). ${ }^{3}$ However, early symptoms are vague, and overt symptoms usually become manifest only when advanced rightsided heart failure develops. Thus, symptom-guided surgical indications may render surgical outcomes even poorer. ${ }^{4}$

Operative mortality of up to $36 \%$ has been reported for primary TR surgery, and this renders surgeons wary of opting for surgical intervention. ${ }^{7,9,10}$ Long-term outcomes are also reported to be poor, for instance, Iscan and colleagues ${ }^{8}$ found that the 10-year survival after TV replacement for patients aged $33 \pm 15$ years was less than $40 \%$.

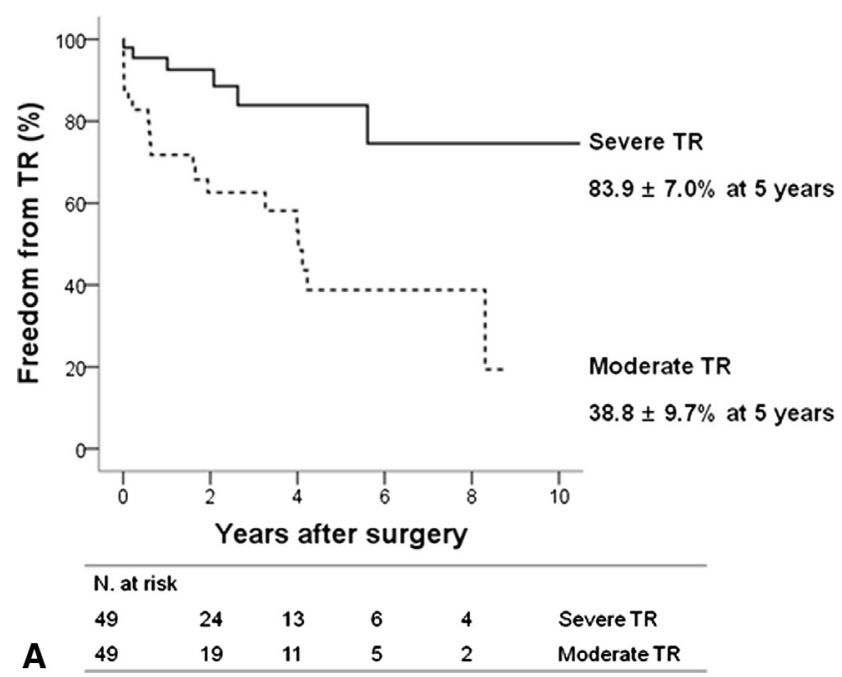

According to several recent reports, clinical outcomes after isolated TV surgery are mainly influenced by preoperative clinical parameters; thus, overall long-term outcomes may be improved by appropriate patient selection and early surgical referral. ${ }^{4,6,13}$ Topilsky and colleagues ${ }^{6}$ performed a retrospective analysis of the data of 189 patients who underwent TV replacement for severe TR. Operative mortality was $10 \%$, and the 5 -year survival was $55.9 \%$. The authors found that long-term survival was affected by preoperative parameters, such as advanced heart failure symptoms, Charlson comorbidity index, RV function, and serum creatinine level; therefore, they concluded that TV replacement can be performed with acceptable early and long-term outcomes if patients undergo surgery before the onset of rightsided heart failure or end-organ damage.

Lee and colleagues ${ }^{14}$ used propensity score matching to compare the rate of long-term mortality between patients undergoing surgical or medical treatment for isolated TR and found that the survival was superior in the surgery group. This finding indicates that TV surgery is not such a high-risk procedure as traditionally believed and that early surgical intervention can improve survival in patients with severe isolated TR.

A recent report by Kim and colleagues ${ }^{4}$ is one of the largest series of isolated TV surgery patients reported to date. They showed that preoperative hemoglobin level and RV end-systolic area were independent determinants of eventfree survival after isolated TV surgery in 61 consecutive patients. However, their report contains heterogeneous populations with primary and secondary TR, because it includes patients who had undergone previous left-sided heart valve surgery $(n=57)$. The pathophysiology of TR development in such patients is likely to differ from that of patients with no history of heart surgery because left

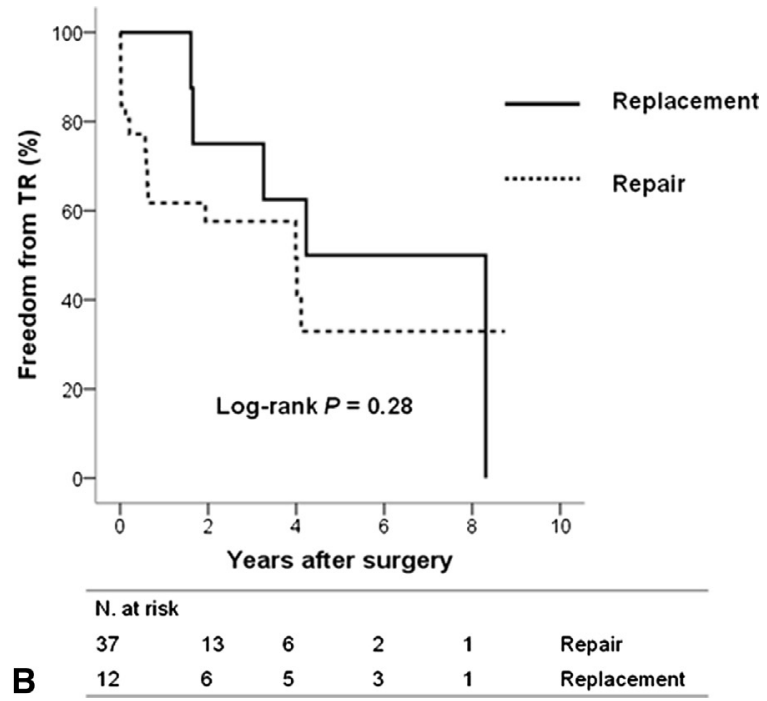

FIGURE 3. Freedom from moderate-to-severe TR curves. A, Separate curves for freedom from severe TR (solid line) and freedom from moderate-tosevere TR (dotted line). B, Freedom from moderate-to-severe TR curves, according to surgery type (repair vs replacement). TR, Tricuspid regurgitation. 


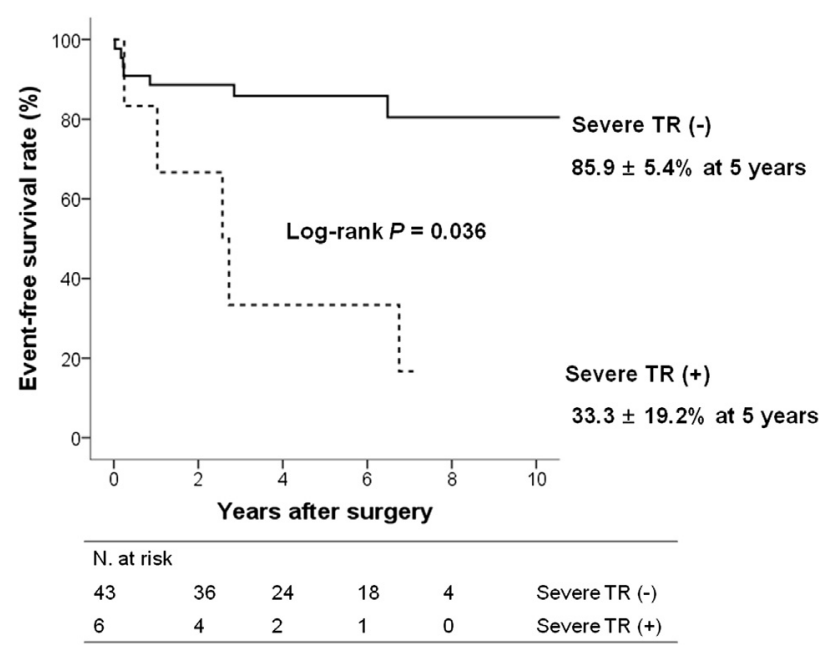

FIGURE 4. Event-free survival curves according to the presence of severe postoperative TR. TR, Tricuspid regurgitation.

atrial pressure/volume overload and subsequent pulmonary hypertension may be implicated in most cases. These 2 populations (primary vs secondary TR) may have a completely different long-term prognosis.

The present study revealed that significant postoperative TR, which was seen in patients who had undergone TV repair, was associated with poor clinical outcomes. Although the TV leaflet morphology and degree of tethering were considered suitable for repair, and TV function seemed satisfactory immediately after TV repair, late postoperative moderate-to-severe TR developed in a significant proportion of patients. The recurrence of TR was time-related through long-term follow-up (Figure 3). The present findings suggest that patients with a higher risk of postoperative TR may benefit from TV replacement with a mechanical prosthesis. This hypothesis is supported by the results of a recent study by Moraca and colleagues, ${ }^{15}$ in which propensity score matching showed that TV replacement resulted in survival and event-free survival similar to those for TV repair. Their results imply that TV replacement should be considered in patients with a reasonable risk of regurgitation recurrence after repair.

In the present cohort, echocardiographic assessments revealed that the durability of bioprosthetic valves was less than expected. Severe postoperative TR at 19.3 to 50.7 months after surgery developed in 4 of 10 patients with bioprosthetic valves. In 2 of these patients, moderate tricuspid stenosis was also observed. All 4 patients had leaflet motion limitation with noncalcified thickening. One of the 4 patients underwent heart transplantation 30.9 months postoperatively for severe RV failure, and subsequent examination of the explanted TV prosthesis by a pathologist confirmed degenerative thickening of valve leaflets. By contrast, Dalrymple-Hay and colleagues ${ }^{16}$ reported excellent durability of bioprosthetic valves. Freedom from TV reoperation in their cohort was $71.0 \% \pm 2.8 \%$ at 15 years, which was similar to that observed for mechanical valve replacement. A meta-analysis of 11 published studies comparing surgical outcomes between bioprosthesis and mechanical valves for $\mathrm{TV}$ replacement revealed that the differences in reoperation rates or survival were trivial and insignificant up to year 10. ${ }^{17}$ However, a low reoperation rate cannot be considered an entirely satisfactory surrogate for excellent durability. In particular, given that candidates for TV reoperation are likely to experience an exacerbation of preexisting RV dysfunction and that the operative risk may thus be unacceptably high, the decision as to whether to perform TV reoperation is challenging. In this situation, patients with significant postoperative TR are more likely to receive conservative medical treatment to control their heart failure than to undergo TV reoperation. Few studies have evaluated the durability of bioprosthetic valves in TV surgery on the basis of echocardiographic evaluations performed long after surgery. In the present study, only 1 of the 4 patients with significant postoperative TR after bioprosthetic valve implantation underwent cardiac reoperation for TR (heart transplantation). This finding supports the hypothesis that TV reoperation cannot be a complete surrogate for TV dysfunction after surgery.

The present study showed that the presence of renal or hepatic dysfunction, evidenced by a high bilirubin level and decreased estimated glomerular filtration rate, was associated with poor clinical outcomes. In the same context, Ailawadi and colleagues ${ }^{18}$ suggested a more comprehensive model for organ dysfunction to predict mortality after TV surgery. The Model for End-Stage Liver Disease score, which is calculated from baseline bilirubin, international normalized ratio, and creatinine, was used in their study including 168 patients undergoing TV surgery. Because the Model for End-Stage Liver Disease score accurately predicted mortality, the authors concluded that the model can offer a simple and effective method of risk stratification in these patients.

\section{Study Limitations}

The present study has several limitations. First, the study was retrospective and observational, and therefore had limitations inherent to this type of study design. Second, the sample size was small, and thus no robust conclusions can be drawn, although our sample size was relatively large compared with previous studies. Third, sophisticated variables, such as the tricuspid annular dimension, degree of TV tethering, and quantitative parameters of RV function, could not be estimated.

\section{CONCLUSIONS}

Long-term clinical outcomes after surgical correction for severe isolated TR were mainly determined by preoperative factors, such as anemia, renal/hepatic dysfunction, and degree of RV dilatation. These outcomes were not influenced 
by the type of surgery. The present findings suggest that timely surgery is indicated before the development of anemia or organ dysfunctions, and that the TV procedure can be selected according to the clinical status of the individual patient and at the discretion of the attending surgeon.

\section{References}

1. Nath J, Foster E, Heidenreich PA. Impact of tricuspid regurgitation on long-term survival. J Am Coll Cardiol. 2004;43:405-9.

2. Bonow RO, Carabello BA, Chatterjee K, de Leon AC Jr, Faxon DP, Freed MD, et al. ACC/AHA 2006 guidelines for the management of patients with valvular heart disease: a report of the American College of Cardiology/American Heart Association Task Force on Practice Guidelines (writing Committee to Revise the 1998 guidelines for the management of patients with valvular heart disease) developed in collaboration with the Society of Cardiovascular Anesthesiologists endorsed by the Society for Cardiovascular Angiography and Interventions and the Society of Thoracic Surgeons. J Am Coll Cardiol. 2006;48: e1-148.

3. Bonow RO, Carabello BA, Kanu C, de Leon AC Jr, Faxon DP, Freed MD, et al. ACC/AHA 2006 guidelines for the management of patients with valvular heart disease: a report of the American College of Cardiology/American Heart Association Task Force on Practice Guidelines (writing committee to revise the 1998 Guidelines for the Management of Patients With Valvular Heart Disease): developed in collaboration with the Society of Cardiovascular Anesthesiologists: endorsed by the Society for Cardiovascular Angiography and Interventions and the Society of Thoracic Surgeons. Circulation. 2006;114: e84-231.

4. Kim YJ, Kwon DA, Kim HK, Park JS, Hahn S, Kim KH, et al. Determinants of surgical outcome in patients with isolated tricuspid regurgitation. Circulation. 2009;120:1672-8.

5. Lee JW, Choo SJ, Kim KI, Song JK, Kang DH, Song JM, et al. Atrial fibrillation surgery simplified with cryoablation to improve left atrial function. Ann Thorac Surg. 2001;72:1479-83
6. Topilsky Y, Khanna AD, Oh JK, Nishimura RA, Enriquez-Sarano M, Jeon YB, et al. Preoperative factors associated with adverse outcome after tricuspid valve replacement. Circulation. 2011;123:1929-39.

7. Bernal JM, Morales D, Revuelta C, Llorca J, Gutierrez-Morlote J, Revuelta JM. Reoperations after tricuspid valve repair. J Thorac Cardiovasc Surg. 2005;130: 498-503.

8. Iscan ZH, Vural KM, Bahar I, Mavioglu L, Saritas A. What to expect after tricuspid valve replacement? Long-term results. Eur J Cardiothorac Surg. 2007;32: 296-300.

9. Rogers JH, Bolling SF. The tricuspid valve: current perspective and evolving management of tricuspid regurgitation. Circulation. 2009;119:2718-25.

10. Singh SK, Tang GH, Maganti MD, Armstrong S, Williams WG, David TE, et al. Midterm outcomes of tricuspid valve repair versus replacement for organic tricuspid disease. Ann Thorac Surg. 2006;82:1735-41.

11. Shiran A, Sagie A. Tricuspid regurgitation in mitral valve disease incidence, prognostic implications, mechanism, and management. J Am Coll Cardiol. 2009;53:401-8

12. Gonzalez-Vilchez F, Zarauza J, Vazquez de Prada JA, Martin Duran R, Ruano J, Delgado C, et al. Assessment of tricuspid regurgitation by Doppler color flow imaging: angiographic correlation. Int J Cardiol. 1994;44:275-83.

13. Sung K, Park PW, Park KH, Jun TG, Lee YT, Yang JH, et al. Is tricuspid valve replacement a catastrophic operation? Eur J Cardiothorac Surg. 2009;36:825-9.

14. Lee JW, Song JM, Park JP, Kang DH, Song JK. Long-term prognosis of isolated significant tricuspid regurgitation. Circ J. 2010;74:375-80.

15. Moraca RJ, Moon MR, Lawton JS, Guthrie TJ, Aubuchon KA, Moazami N, et al. Outcomes of tricuspid valve repair and replacement: a propensity analysis. Ann Thorac Surg. 2009;87:83-8.

16. Dalrymple-Hay MJ, Leung Y, Ohri SK, Haw MP, Ross JK, Livesey SA, et al. Tricuspid valve replacement: bioprostheses are preferable. J Heart Valve Dis. 1999; 8:644-8.

17. Rizzoli G, Vendramin I, Nesseris G, Bottio T, Guglielmi C, Schiavon L. Biological or mechanical prostheses in tricuspid position? A meta-analysis of intrainstitutional results. Ann Thorac Surg. 2004;77:1607-14.

18. Ailawadi G, Lapar DJ, Swenson BR, Siefert SA, Lau C, Kern JA, et al. Model for end-stage liver disease predicts mortality for tricuspid valve surgery. Ann Thorac Surg. 2009;87:1460-7. 